\title{
The State of Psychoemotional, Cytokine Status and Endothelial Function in Patients with Combined Surgical Pathology of the Abdominal Cavity, True Pelvis and Anterior Abdominal Wall, Depending on the Methodic of Simultaneous Surgical Intervention
}

\author{
Lesya N. Gumenyuk ${ }^{1, *}$, Oksana Yu. Gerbali ${ }^{2}$ and Vyacheslav Yu. Mykhaylichenko ${ }^{3}$
}

${ }^{1}$ Faculty of Training of Medical Personnel of the Highest Qualification and Additional Vocational Education, Department of Psychiatry, Narcology, Psychotherapy with the Course of General and Medical Psychology, Medical Academy named after S.I. Georgievsky, Vernadsky Crimea Federal University, 294006, Lenin Ave. 5/7, Simferopol, Russian Federation

2I Faculty of Medicine, Department of Surgery No. 1, Medical Academy named after S.I. Georgievsky, Vernadsky Crimea Federal University, 294006, Lenin Ave. 5/7, Simferopol, Russian Federation

${ }^{3}$ International Faculty, Department of General Surgery, Medical Academy named after S.I. Georgievsky, Vernadsky Crimea Federal University, 294006, Lenin Ave. 5/7, Simferopol, Russian Federation

\begin{abstract}
The relevance of the study is in the fact that disorders of vascular and psychoneuroendocrine genesis often accompany surgical diseases, the issue of ensuring patient safety in the perioperative period remains the basic focus of modern clinical surgery. The purpose of the study is to identify changes in the level of pro-inflammatory cytokines and the functional state of the endothelium, and also to establish whether the transferred simultaneous surgical interventions intensified pro-inflammatory cytokines and changes in the functional state of the endothelium. In this article, changes in the level of proinflammatory cytokines and the functional state of the endothelium are studied, as well as the relationship of these changes with comorbid psychoemotional disorders when performing simultaneous surgical interventions by laparoscopic and open methods in combined diseases of organs of the abdominal and anterior abdominal wall. The authors carried out a prospective, randomized controlled study of 586 patients aged 18 to 72 years who underwent planned simultaneous surgical intervention (SSI) with combined diseases of the abdominal cavity, pelvis and anterior abdominal wall. In the course of the comparative analysis, a general trend was established: the simultaneous surgical interventions caused intensification of proinflammatory cytokines and changes in the functional state of the endothelium.
\end{abstract}

Keywords: Simultaneous surgical interventions, Fast Track Surgery, proinflammatory cytokines, endothelial function, psychoemotional disorders.

\section{INTRODUCTION}

According to some studies, in recent years, there has been an increase in the number of patients who have combined surgical diseases. The frequency of pathologies requiring simultaneous surgical correction is from 4.8 to $30 \%$, which led to an increase in the simultaneous surgical intervention (SSI) performed by both traditional and laparoscopic access [1, 2]. Considering the fact that surgical diseases are often accompanied by diseases of vascular and psychoneuroendocrine origin, the issue of ensuring patient safety in the perioperative period remains the basic direction of modern clinical surgery [3]. In recent years, more and more interest induces the concept of "Fast Track Surgery", which implies an accelerated recovery and reduction in the frequency of

*Address correspondence to this author at the Faculty of Training of Medical Personnel of the Highest Qualification and Additional Vocational Education, Department of Psychiatry, Narcology, Psychotherapy with the Course of General and Medical Psychology, Medical Academy named after S.I. Georgievsky, Vernadsky Crimea Federal University, 294006, Lenin Ave. 5/7, Simferopol, Russian Federation; E-mail: konghasung@gmail.com postoperative complications through the use of special anesthesia, non-narcotic anesthesia in the postoperative period, the reduction of infusion therapy, the minimally invasive surgical benefit, early oral nutrition, stressful response of the body to surgical intervention, which, in turn, helps to reduce the duration of stay patient in hospital and rapid recovery of the quality of life [4-7]. Despite a large number of works devoted to the study of the safety and effectiveness of "Fast Track Surgery", the results obtained are sometimes contradictory, and, as a rule, concern isolated surgical interventions. The role of the psychoemotional state of patients in the development of surgical stress remains poorly studied.

Given the fact that the severity of the systemic inflammatory response in the postoperative period determined by the activation of pro-inflammatory cytokines and functional state of the endothelium of direct relevance to the development of multiple organ dysfunction, timely evaluation of the above markers after performing a surgical intervention, depending on the method of rapid access and features perioperative 
management of the patient is necessary for assessing the patient's condition and the effectiveness of simultaneous therapy. In connection with the above, the study of the dynamics of the pro-inflammatory cytokine status and endothelial function, the relationship of these changes to the psycho-comorbid disorders in the perioperative period in patients with concomitant abdominal pathology using laparoscopic and traditional access $\mathrm{SSI}$ is relevant and requires further investigation. The aim of the study was to study the changes in the level of proinflammatory cytokines and the functional state of the endothelium, as well as the relationship of these changes with comorbid psychoemotional disorders when performing simultaneous operative interventions with laparoscopic (with the perioperative period administered by "Fast Track Surgery" and traditionally) and with open methods for combined diseases of the abdominal organs and anterior abdominal wall. Also, to establish whether the transferred simultaneous surgical interventions intensified pro-inflammatory cytokines and changes in the functional state of the endothelium.

\section{MATERIALS AND METHODS}

Based on informed consent, following the standards of the Ethics Committee of the Russian Federation, a prospective, randomized controlled trial of 586 patients aged 18 to 72 years old who underwent planned SSI with combined diseases of the abdominal cavity, true pelvis and anterior abdominal wall. The criteria for inclusion in the study were: 1) age over 18 ; 2) the planned nature of the intervention; 3) physical status by ASA; 4) the transferred isolated, simultaneous laparoscopic and traditional (open) surgical interventions for the combined pathology of the abdominal cavity organs and the anterior abdominal wall; 4) absence of acute inflammatory diseases, 5) absence of psychic, psycho-organic and exogenous diseases of the brain; 6) signed informed consent to participate in the study. The average age of patients is $49.2 \pm 6.9$ years. Among them $-420(71.7 \%)$ women and $166(28.3 \%)$ men. The first group consisted of 196 patients who underwent laparoscopic SSI using the "Fast Track Surgery" program. The second - 195 patients who underwent laparoscopic SSI with traditional management in the perioperative period. The third group consisted of 195 patients who underwent traditional SSI with traditional management during the perioperative period. In terms of the severity of surgical pathology and comorbid somatic diseases, 29 (4.9\%) patients were classified as I, $241(41.2 \%)$ as II, 224 $(38.2 \%)$ as III and $92(15.7 \%)$ of the patient - to the IV degree of operational - anesthesiological risk according to ASA. The demographic profile of patients is presented in Table 1.

Table 1: Demographic Profile of Patients

\begin{tabular}{|c|c|c|c|}
\hline Index & Group 1 & Group 2 & Group 3 \\
\hline \hline Age & $48.2 \pm 6.9$ & $49.3 \pm 6.6$ & $50.0 \pm 6.9$ \\
\hline Gender (W:M) & $139: 57$ & $141: 54$ & $140: 55$ \\
\hline Total & 196 & 195 & 195 \\
\hline
\end{tabular}

Groups of patients were match age $(p=0.807$, twosided $t$-criterion of Student), sex $(p=0,94, x 2)$, diagnosis of underlying disease $(p=0,895, x 2)$, degree of operative-anesthesiological risk of ASA ( $p=0,737$, $x 2)$, intraoperative parameters $(p=0,806, x 2)$, which allowed to carry out an analytical evaluation of the results of the study as objectively and reliably as possible. In all patients, the basic surgical disease was chronic calculous cholecystitis (CCC). The structure of the concomitant surgical pathology is presented in Table 2. In 249 (63.6\%), a comorbid somatic pathology was established, in which the structure was dominated by hypertension, diabetes, obesity, hypothyroidism, chronic stomach diseases, chronic pyelonephritis, varicose veins of the lower extremities. The index of comorbidity Charlson averaged $5.6 \pm 0.84$.

In the process of work, general clinical, clinicallaboratory and statistical methods were used. Investigation of inflammatory markers included the study of the concentration of C-reactive protein and pro-inflammatory cytokines (IL-6, IL-8, tumour necrosis factor-alpha (TNF-a) in the blood serum. The process used the "sandwich" - variant of the solid-phase enzyme immunoassay (biotin-streptavidin system of signal amplification and test system of ZAO firm Vector-Best, Novosibirsk). Serum samples were stored frozen at $-200 \mathrm{C}$. The evaluation of the functional state of the endothelium was based on the determination of total nitric oxide (NO) and endothelium-1 (ET-1) in blood plasma, as well as their ratios. The method of enzyme immunoassay was used (test systems "SYSTEMS", USA and "BIOMEDICA GRUPPE", USA). Control points of the study: immediately before the operation, 1, 24, 72 hours and 7 days after the operation. The study of the psychoemotional state of patients was performed in the preoperative period in two stages: the first stage included a screening assessment using the method of express diagnostics of anxiety-depressive disorders of V.N. Krasnov [8]; the 
Table 2: Structure of Concomitant Surgical Pathology of Abdominal Organs

\begin{tabular}{|c|c|c|c|}
\hline Concomitant Surgical Diseases & Group 1 & Group 2 & Group 3 \\
\hline $\mathrm{CCC}+$ peritoneal commissures disease & $47(24.0 \%)$ & $48(24.6 \%)$ & $54(27.7 \%)$ \\
\hline $\begin{array}{l}\mathrm{CCC}+\text { postoperative herniation of the anterior } \\
\text { of the abdominal wall }\end{array}$ & $44(22.4 \%)$ & $45(23.1 \%)$ & $40(20.5 \%)$ \\
\hline $\mathrm{CCC}+$ umbilical hernia + peritoneal commissures disease & $31(15.8 \%)$ & $26(13.3 \%)$ & $23(11.8 \%)$ \\
\hline $\mathrm{CCC}+$ non-parasitic liver cyst & $12(6.1 \%)$ & $13(6.7 \%)$ & $15(7.7 \%)$ \\
\hline $\mathrm{CCC}+$ cyst of the upper pole of the kidney & $14(7.1 \%)$ & $11(5.6 \%)$ & $13(6.7 \%)$ \\
\hline $\mathrm{CCC}+$ inguinal hernia + peritoneal commissures disease & $13(6.6 \%)$ & $12(6.2 \%)$ & $9(4.6 \%)$ \\
\hline $\begin{array}{c}\text { CCC + sliding hernia of esophageal opening } \\
\text { of diaphragm }\end{array}$ & $12(6.1 \%)$ & $11(5.6 \%)$ & $9(4.6 \%)$ \\
\hline $\mathrm{CCC}+\mathrm{a}$ hernia of a white line of a stomach & $9(4.6 \%)$ & $10(5.1 \%)$ & $13(6.7 \%)$ \\
\hline $\mathrm{CCC}+$ liver echinococcosis & $8(4.1 \%)$ & $11(5.6 \%)$ & $9(4.6 \%)$ \\
\hline $\mathrm{CCC}+$ postoperative ventral hernia + peritoneal commissures disease & $4(2.0 \%)$ & $6(3.1 \%)$ & $6(3.1 \%)$ \\
\hline $\mathrm{CCC}+$ nonspecific ulcerative colitis & $2(1.0 \%)$ & $2(1.0 \%)$ & $4(2.1 \%)$ \\
\hline Total & 196 & 195 & 195 \\
\hline
\end{tabular}

second is to determine the severity of anxiolytic and depressive symptoms using objective, quantified clinical scales HAM-A and HDRS [9]. The integrative value was calculated on the basis of the totality of the values of the selected answers on the methodology questions [10].

Statistical processing of the data obtained during the research was carried out using the statistical package SPSS 19.0. As descriptive statistics for quantitative data, the arithmetic mean (M) was used as a measure of the central trend, the standard deviation and the standard error as measures of variability ( $m$ $( \pm))$. To determine the statistical significance of differences in mean values of the criterion, the Student's criterium was used (for unrelated or linked samples, depending on the task). The calculations were carried out in the Medstat licensed software, with a preliminary check of the distribution of the series of data on the normality of the distribution of $\mathrm{W}$ criterion by Shapiro-Wilk's. In this statistical package, Student's criterion provides for corrections for a possible dispersion inequality with an insignificant difference in distribution from the normal one. To reveal not only the degree of proximity (correlation) of indicators but also the structure proper, the procedure of tree-like clustering was applied. As a way of combining variables into clusters, the Ward method was used as one of the most effective and as a measure of the distance between variables - the quantity (1-r), where $r$ is the correlation coefficient.

\section{RESULTS AND DISCUSSION}

A psychometric study of the patients' psychological state on the HAM-A and HADS scales in the preoperative period revealed signs of anxiety disorder and interoceptive somatogenic depression of varying severity in $100.0 \%$ of patients. Clinically expressed conditions were diagnosed in 341 (58.2\%), subdepressive and separate, clinically unreported anxiety symptoms, which occurred in 245 (41.8\%) persons, are regarded by us as signs of mental sub-adaptation. Among the leading syndromes of psychoemotional disorders, the following were identified in the surveyed: anxious (agitated) in 23 (40.7\%), melancholy (melancholic) - in $12(32.7 \%)$, Sinestro-hypochondriac in $23(20.3 \%)$ and astheno-anergic - in $2(4.6 \%)$.

In the course of studying the dynamics of markers (proinflammatory cytokines) of the systemic inflammatory response, the following features were established (Table 3 ): in the preoperative period the index of C-reactive protein, IL-6, IL-8 and TNF-a values significantly exceeded the values in $\mathrm{CG}$ and made at LSSI- F - $4.7 \pm 0.5 \mathrm{pg} / \mathrm{ml}(\mathrm{p}=0.002), 5.9 \pm 0.4 \mathrm{pg} / \mathrm{ml}$ $(p<0.001), 11.2 \pm 0.9 \mathrm{pg} / \mathrm{ml}(\mathrm{p}=0.044)$ and $12.4 \pm 1.0$ $(p<0.001) \mathrm{pg} / \mathrm{ml}$, respectively; with LSSI, the Creactive protein level was $5.2 \pm 0.6 \mathrm{pg} / \mathrm{ml}(p<0.001)$, IL-6 - $6.0 \pm 0.7 \mathrm{pg} / \mathrm{ml}(\mathrm{p}<0.001), \mathrm{IL}-8-12,3 \pm 1.0$ $\mathrm{pg} / \mathrm{ml}(\mathrm{p}=0.006)$, TNF-a $-13.2 \pm 1.1 \mathrm{pg} / \mathrm{ml}(\mathrm{p}$ $<0.001)$ and with TSSI $-5.1 \pm 0.6 \mathrm{pg} / \mathrm{ml}(\mathrm{p}<0.001)$, $5.7 \pm 0.6 \mathrm{pg} / \mathrm{ml}(\mathrm{p}<0.001), 11.9 \pm 0.8 \mathrm{pg} / \mathrm{ml}(\mathrm{p}=$ $0.006)$ and $5.7 \pm 0.6 \mathrm{pg} / \mathrm{ml}(\mathrm{p}<0.001)$, respectively, 
Table 3: Dynamics of the Proinflammatory Cytokines

\begin{tabular}{|c|c|c|c|c|c|c|c|}
\hline \multicolumn{3}{|c|}{ Measuring points } & № & C- reactive protein & IL-6 & IL-8 & TNF- $\alpha$ \\
\hline \multicolumn{3}{|c|}{ Control Group } & 1 & $3.1 \pm 0.3$ & $2.4 \pm 0.2$ & $9.2 \pm 0.5$ & $5.2 \pm 0.3$ \\
\hline \multirow{3}{*}{\multicolumn{2}{|c|}{ Before the surgery }} & LSSI-F & 2 & $\begin{array}{c}4.7 \pm 0.5 \\
p_{21}=0.002\end{array}$ & $\begin{array}{c}5.9 \pm 0.4 \\
\mathrm{p}_{21}<0.001\end{array}$ & $\begin{array}{c}11.2 \pm 0.9 \\
\mathrm{p}_{21}=0.044\end{array}$ & $\begin{array}{c}12.4 \pm 1.0 \\
\mathrm{p}_{21}<0.001\end{array}$ \\
\hline & & LSSI & 3 & $\begin{array}{c}5.2 \pm 0.6 \\
p_{31}<0.001\end{array}$ & $\begin{array}{c}6.0 \pm 0.7 \\
p_{31}<0.001\end{array}$ & $\begin{array}{c}12.3 \pm 1.0 \\
p_{31}=0.006\end{array}$ & $\begin{array}{c}13.2 \pm 1.1 \\
p_{31}<0.001\end{array}$ \\
\hline & & TSSI & 4 & $\begin{array}{c}5.1 \pm 0.6 \\
p_{41}<0.001\end{array}$ & $\begin{array}{c}5.7 \pm 0.6 \\
p_{41}<0.001\end{array}$ & $\begin{array}{c}11.9 \pm 0.8 \\
\mathrm{p}_{41}=0.006\end{array}$ & $\begin{array}{c}11.9 \pm 1.4 \\
p_{41}<0.001\end{array}$ \\
\hline & \multirow{3}{*}{$1 \mathrm{~h}$} & LSSI-F & 5 & $\begin{array}{c}10.3 \pm 0.8 \\
p_{51}<0.001\end{array}$ & $\begin{array}{c}7.2 \pm 0.7 \\
p_{51}<0.001\end{array}$ & $\begin{array}{c}25.3 \pm 1.8 \\
p_{51}<0.001\end{array}$ & $\begin{array}{c}23.6 \pm 1.8 \\
p_{51}<0.001\end{array}$ \\
\hline & & LSSI & 6 & $\begin{array}{c}11.1 \pm 0.8 \\
p_{61}<0.001\end{array}$ & $\begin{array}{c}7.8 \pm 0.7 \\
\mathrm{p}_{61}<0.001\end{array}$ & $\begin{array}{c}26.3 \pm 1.9 \\
\mathrm{p}_{61}<0.001\end{array}$ & $\begin{array}{c}25.1 \pm 1.6 \\
\mathrm{p}_{61}<0.001\end{array}$ \\
\hline & & TSSI & 7 & $\begin{array}{c}12.1 \pm 0.8 \\
p_{71}<0.001\end{array}$ & $\begin{array}{c}8.6 \pm 0.7 \\
p_{71}<0.001\end{array}$ & $\begin{array}{c}28.7 \pm 1.8 \\
\mathrm{p}_{71}<0.001\end{array}$ & $\begin{array}{c}22.6 \pm 1.5 \\
\mathrm{p}_{71}<0.001\end{array}$ \\
\hline & \multirow{3}{*}{$24 \mathrm{~h}$} & LSSI-F & 8 & $\begin{array}{c}23.2 \pm 1.7 \\
p_{81}<0.001\end{array}$ & $\begin{array}{c}14.4 \pm 0.9 \\
p_{81}<0.001\end{array}$ & $\begin{array}{c}22.3 \pm 1.4 \\
\mathrm{p}_{81}<0.001\end{array}$ & $\begin{array}{c}37.8 \pm 1.9 \\
\mathrm{p}_{81}<0.001\end{array}$ \\
\hline & & LSSI & 9 & $\begin{array}{c}24.3 \pm 1.9 \\
p_{91}<0.001\end{array}$ & $\begin{array}{c}15.6 \pm 1.0 \\
p_{91}<0.001\end{array}$ & $\begin{array}{c}21.5 \pm 1.4 \\
p_{91}<0.001\end{array}$ & $\begin{array}{c}40.2 \pm 2.2 \\
p_{91}<0.001\end{array}$ \\
\hline & & TSSI & 10 & $\begin{array}{c}30.1 \pm 1.8 \\
p_{10-1}<0.001 \\
p_{10-8}=0.004 \\
p_{10-9}=0.027\end{array}$ & $\begin{array}{c}30.1 \pm 1.9 \\
p_{10-1}<0.001 \\
p_{10-8}<0.001 \\
p_{10-9}<0.001\end{array}$ & $\begin{array}{c}28.8 \pm 1.5 \\
p_{10-1}<0.001 \\
p_{10-8}=0.001 \\
p_{10-9}<0.001\end{array}$ & $\begin{array}{c}85.9 \pm 1.9 \\
\mathrm{p}_{10-1}<0.001 \\
\mathrm{p}_{10-8}<0.001 \\
\mathrm{p}_{10-9}<0.001\end{array}$ \\
\hline & \multirow{3}{*}{$72 \mathrm{~h}$} & LSSI-F & 11 & $\begin{array}{c}13.3 \pm 0.9 \\
\mathrm{p}_{11-1}<0.001\end{array}$ & $\begin{array}{c}6.8 \pm 0.3 \\
\mathrm{p}_{11-1}<0.001\end{array}$ & $\begin{array}{c}15.6 \pm 1.0 \\
p_{11-1}<0.001\end{array}$ & $\begin{array}{c}15.1 \pm 1.1 \\
p_{11-1}<0.001\end{array}$ \\
\hline & & LSSI & 12 & $\begin{array}{c}12.9 \pm 0.8 \\
\mathrm{p}_{12-1}<0.001\end{array}$ & $\begin{array}{c}8.4 \pm 0.5 \\
\mathrm{p}_{12-1}<0.001 \\
\mathrm{p}_{12-11}=0.007\end{array}$ & $\begin{array}{c}16.6 \pm 1.2 \\
p_{12-1}<0.001\end{array}$ & $\begin{array}{c}21.7 \pm 1.7 \\
p_{12-11}=0.004\end{array}$ \\
\hline & & TSSI & 13 & $\begin{array}{c}22.3 \pm 1.8 \\
\mathrm{p}_{13-1}<0.001 \\
\mathrm{p}_{13-11}<0.001 \\
\mathrm{p}_{13-12}<0.001\end{array}$ & $\begin{array}{c}14.3 \pm 1.0 \\
\mathrm{p}_{13-1}<0.001 \\
\mathrm{p}_{13-11}<0.001 \\
\mathrm{p}_{13-12}<0.001\end{array}$ & $\begin{array}{c}22.1 \pm 1.9 \\
\mathrm{p}_{13-1}<0.001 \\
\mathrm{p}_{13-11}<0.001 \\
\mathrm{p}_{13-12}<0.001\end{array}$ & $\begin{array}{c}42.8 \pm 2.2 \\
p_{13-1}<0.001 \\
p_{13-11}<0.001 \\
p_{13-12}<0.001\end{array}$ \\
\hline & \multirow{3}{*}{$7 d$} & LSSI-F & 14 & $\begin{array}{c}6.2 \pm 0.9 \\
p_{14-1}=0.002\end{array}$ & $\begin{array}{c}5.4 \pm 0.2 \\
\mathrm{p}_{14-1}<0.001\end{array}$ & $11.2 \pm 1.0$ & $\begin{array}{c}7.2 \pm 0.3 \\
\mathrm{p}_{14-1}<0.001\end{array}$ \\
\hline & & LSSI & 15 & $\begin{array}{c}6.1 \pm 1.0 \\
p_{15-1}=0.003\end{array}$ & $\begin{array}{c}6.8 \pm 0.3 \\
\mathrm{p}_{15-1}<0.001\end{array}$ & $\begin{array}{c}12.3 \pm 1.2 \\
p_{15-1}=0.021\end{array}$ & $\begin{array}{c}11.9 \pm 0.8 \\
\mathrm{p}_{15-14}<0.001\end{array}$ \\
\hline & & TSSI & 16 & $\begin{array}{c}9,2 \pm 0,9 \\
\mathrm{p}_{16-1}<0,001 \\
\mathrm{p}_{16-14}=0,015 \\
\mathrm{p}_{16-15}=0,012\end{array}$ & $\begin{array}{c}7,8 \pm 0,4 \\
\mathrm{p}_{16-1}<0,001 \\
\mathrm{p}_{16-14}<0,001 \\
\mathrm{p}_{16-15}=0,047\end{array}$ & $\begin{array}{c}16,7 \pm 1,4 \\
\mathrm{p}_{16-1}<0,001 \\
\mathrm{p}_{16-14}<0,001 \\
\mathrm{p}_{16-15}=0,010\end{array}$ & $\begin{array}{c}14,1 \pm 0,6 \\
p_{16-1}<0,001 \\
p_{16-14}<0,001 \\
p_{16-15}=0,027\end{array}$ \\
\hline
\end{tabular}

Note: (the studied indices decreased in 1.9 and 1.7 times, $p>0.05$, in 1.3 and 1.4 times, $p>0.05$ respectively), changes in IL-6 and TNF- $\alpha$ were carried less pronounced (2.1 and 1.9 times after LSSI and 2.1 times after LSSI-F, $p=0.007$ and 2.5 times, $p=0.004$, respectively).

which is explained by the presence of a chronic inflammatory process. The level of proinflammatory cytokines in the studied groups did not have statistically significant differences $(p>0.05)$.

In the postoperative period 1 hour after surgery, a significant $(p<0.001)$ increase in proinflammatory cytokines was registered in all the groups, reflecting the onset of a protective inflammatory reaction: the concentration of C-reactive protein exceeded the preoperative values by 2.2 times, the LSSI in 2.1 times, TSSI - 2.4 times, IL-6 - 1.2, 1.3 and 1.5 times, respectively), the IL-8 index after the performed LSSI-F 
increased by 2.3 times, LSSI -2.2 times, TSSI -2.4 times and TNF-a - 1.9 times, after LSSI - 1.9 times, TSSI - 1.9 times. There were no significant differences in the parameters studied between the groups $(p>$ 0.05). By the end of the first day after the operation (the period of growth of organ dysfunctions), regardless of the technique used, the level of values of proinflammatory cytokines tended to increase and reached the maximum rise, with the most pronounced growth observed after TSSI: the C-reactive protein concentration exceeded preoperative values of 5,9 times (4.9 times after LSSI-F, $p=0.004$, LSSI 4.7 times, $p=0.027$ ), IL-6 5.3 times (at 2.4, p <0.001 and 2.6 times, $p<0.001$, respectively), IL-8 2.4-fold (after LSSI-F 1.9-fold, $p=0.001$, LSSI-1.7-fold $p<0.001$ ), TNF-a -7.2 times (3.0 times $p<0.001$ and 3.1 times, $p$ $<0.001$, respectively). On the $3 r d$ day after surgery (the period of increased risk of postoperative complications), the level of proinflammatory cytokines significantly decreased after both laparoscopic and traditional SSI. In spite of the fact that after the concentration of the traditional perioperative period, the concentrations of C-reactive protein and IL-8 did not differ significantly from the values of LSSI according to "Fast Track Surgery".

After TSSI, there was also a positive trend: concentration of C-reactive protein decreased by 1.3 times, IL- 6 decreased by 2.1 times, IL- 8 by 1.3 -fold, TNF-a - by 2.0 times, however statistically significantly exceeded the values of LSSI-F $(p<0.001)$ and LSSI ( $p$ $<0.001$ ). The less pronounced intensity of the systemic inflammatory response to surgical intervention in the LSSI-F group facilitated the normalization of the proinflammatory profile at an earlier time and 7 days after the SSI, the indices not only did not have statistically significant differences from the preoperative values but also approached the parameters of CG ( $p>$ 0 . 05). After LSSI, positive dynamics was also observed, however, changes in the indices of the "first cytokine" -IL-6 and TNF-a -were of a less pronounced character in comparison with LSSI-F ( $p=0.001, p$ $<0.001$, respectively). Values of C-reactive protein, IL6, IL-8 and TNF-a had no statistically significant differences from preoperative ( $p>0.05)$, but $C G$ values did not reach $(p=0.003, p<0.001, p=0.021, p<0.001$, respectively). After TSSI, the level of proinflammatory cytokines remained high and significantly $(p<0.05)$ exceeded preoperative values. Despite the fact that the concentration of C-reactive protein decreased by 3.3 times, IL- 6 by 3.9 times, IL- 8 by 1.7 -fold, TNF-a by 6.0 with respect to indicators at 1 -st postoperative day, the changes were less pronounced in comparison with LSSI-F ( $p=0.015, p<0.001, p<0.001, p<0.001$, respectively) and LSSI $(p=0.012, p=0.047, p=$ $0.010, p=0.027$, respectively).

In the course of studying the dynamics of vasoactive factors, which play an important role in the development of various cardiovascular complications, the following peculiarities were established (Table 4): in the preoperative period, endothelin-1 (ET-1) values were significantly $(p<0.001)$ lower relative to the values of the control group and amounted to $30.1 \pm 3.5$ $\mathrm{mmol} / \mathrm{L}$ for LSSI-F, $31.2 \pm 3.9 \mathrm{mmol} / \mathrm{L}$ for LSSI and $31.4 \pm 3.8 \mathrm{mmol} / \mathrm{L}$ for TSSI, and the meaning of nitric oxide (NO) had no statistically significant differences from the control group and were $44.3 \pm 5.0 \mathrm{pg} / \mathrm{ml}$, $43.8 \pm 5.1 \mathrm{pg} / \mathrm{ml}$ and $44.9 \pm 5.1 \mathrm{pg} / \mathrm{ml}$, respectively about. The levels of ET-1 and NO in the study groups were comparable. ( $p>0.05)$. In the postoperative period, $1 \mathrm{~h}$ after operative intervention in groups with the use of laparoscopic access, the parameters of ET-1 decreased slightly relative to preoperative ones but did not reach statistical significance ( $p>0.05$ ): after LSSI-F values of ET-1 decreased 1.1 times, after LSSI - in 1,2 times.

At the same time, after completed TSSI, the level of ET-1 had more pronounced changes (in 1,3 times), which significantly exceeded the indices of LSSI-F ( $p=$ $0,012)$ and LSSI $(p=0,009)$. The level of NO slightly decreased in all groups (after LSSI-F - 1.1 times, LSSI - 1.3 times, TSSI - 1.3 times), but the values did not differ significantly from preoperative and did not have statistical differences between groups. By the end of the first day after SSI, in groups with laparoscopic access, a peak was observed in the reduction of ET-1 indices (2.9-fold after LSOV-F, 3.4-fold in PMOV, p> 0.05 ), and NO (in 2.9 times and 2.7 times, $p>0.05$, respectively), significantly $(p<0.001)$ differing from preoperative values and indices 1 hour after the operation. After TSSI, inverted dynamics was observed: the level of ET-1 increased by 1.7 times, NO-decreased by 1.4 times with respect to preoperative dynamics $(p<0.001)$ and $p=0.038$, respectively) and statistically significantly $(P<0.001)$ increased indicators LSSI and LSSI-F.

On the 3rd day after surgery in groups with laparoscopic access, the values of ET-1 and NO tended to increase with respect to the indices 24 hours after the operation: after LSSI-F - in $1.3(p>0.05)$ and in 1.8 times $(p=0.008)$, respectively, LSSI $-1.4(p>$ $0.05)$ and 1.7 times $(p=0.018)$, respectively. After the 
Table 4: Dynamics of Indicators of the Functional State of the Endothelium

\begin{tabular}{|c|c|c|c|c|c|}
\hline \multicolumn{3}{|c|}{ Measuring points } & & $\mathrm{NO} \mathrm{mmol} / \mathrm{L}$ & $\mathrm{ET}-1 \mathrm{pg} / \mathrm{ml}$ \\
\hline \multicolumn{3}{|c|}{ Control Group } & 1 & $50.7 \pm 4.3$ & $44.7 \pm 5.2$ \\
\hline \multirow{3}{*}{\multicolumn{2}{|c|}{ Before the surgery }} & $\begin{array}{c}\text { LSSI-F } \\
100 \text { people }\end{array}$ & 2 & $\begin{array}{c}30.1 \pm 3.5 \\
\mathrm{p}_{21}<0.001\end{array}$ & $44.3 \pm 5.0$ \\
\hline & & $\begin{array}{c}\text { LSSI } \\
100 \text { people }\end{array}$ & 3 & $\begin{array}{c}31.2 \pm 3.9 \\
\mathrm{p}_{31}<0.001\end{array}$ & $43.8 \pm 5.1$ \\
\hline & & $\begin{array}{c}\text { TSSI } \\
100 \text { people }\end{array}$ & 4 & $\begin{array}{c}31.4 \pm 3.8 \\
\mathrm{p}_{41}<0.001\end{array}$ & $44.9 \pm 5.1$ \\
\hline \multirow[t]{12}{*}{ After the surgery } & \multirow[t]{3}{*}{$1 \mathrm{~h}$} & LSSI-F & 5 & $27.2 \pm 3.2$ & $40.1 \pm 4.8$ \\
\hline & & LSSI & 6 & $24.7 \pm 3.1$ & $39.2 \pm 4.9$ \\
\hline & & TSSI & 7 & $24.9 \pm 3.3$ & $\begin{array}{c}58.1 \pm 5.2 \\
\mathrm{p}_{75}=0.012 \\
\mathrm{p}_{76}=0.009\end{array}$ \\
\hline & \multirow[t]{3}{*}{$24 \mathrm{~h}$} & LSSI-F & 8 & $\begin{array}{c}10.4 \pm 1.1 \\
\mathrm{p}_{82}<0.001\end{array}$ & $\begin{array}{c}27.1 \pm 3.8 \\
\mathrm{p}_{82}<0.001\end{array}$ \\
\hline & & LSSI & 9 & $\begin{array}{c}9.3 \pm 1.0 \\
\mathrm{p}_{93}<0.001\end{array}$ & $\begin{array}{c}26.3 \pm 3.7 \\
p_{93}<0.001\end{array}$ \\
\hline & & TSSI & 10 & $\begin{array}{c}22.6 \pm 1.8 \\
\mathrm{p}_{10-4}=0.038 \\
\mathrm{p}_{10-8}<0.001 \\
\mathrm{p}_{10-9}<0.001\end{array}$ & $\begin{array}{c}76.5 \pm 4.2 \\
\mathrm{p}_{10-4}<0.001 \\
\mathrm{p}_{10-8}<0.001 \\
\mathrm{p}_{10-9}<0.001\end{array}$ \\
\hline & \multirow[t]{3}{*}{$72 \mathrm{~h}$} & LSSI-F & 11 & $\begin{array}{c}18.7 \pm 2.9 \\
\mathrm{p}_{11-2}=0.013\end{array}$ & $35.8 \pm 3.7$ \\
\hline & & LSSI & 12 & $\begin{array}{c}16.2 \pm 2.7 \\
p_{12-3}=0.002\end{array}$ & $36.0 \pm 3.8$ \\
\hline & & TSSI & 13 & $29.6 \pm 3.2$ & $\begin{array}{c}78.3 \pm 4.2 \\
\mathrm{p}_{13-4}<0.001 \\
\mathrm{p}_{13-11}<0.001 \\
\mathrm{p}_{13-12}<0.001\end{array}$ \\
\hline & \multirow[t]{3}{*}{$7 d$} & LSSI-F & 14 & $32.1 \pm 3.7$ & $42.7 \pm 6.0$ \\
\hline & & LSSI & 15 & $31.8 \pm 3.6$ & $43.2 \pm 6.1$ \\
\hline & & TSSI & 16 & $26.1 \pm 3.4$ & $\begin{array}{c}72.4 \pm 6.8 \\
p_{16-4}<0.001 \\
p_{16-14}=0.001 \\
p_{16-15}=0.002\end{array}$ \\
\hline
\end{tabular}

Note. brown - comparison of groups with the control group; blue - comparison of indicators in groups relative to pre-operative; green - intergroup comparison at the control point of the study.

performed TSSI, the level of vasoactive factors studied increased slightly, but these changes were not statistically significant. In this case, despite the relative stability of the NO level, its values were statistically significantly higher than those of LSSI-F $(p<0.001)$ and LSSI $(p<0.001)$. Seven days after surgery in groups 
with laparoscopic access, there was an increase in ET1 and NO, but there were no statistically significant differences $(p>0.05)$ between groups and preoperative values. After TSSI, the level of ET-1 remained high, significantly $(p<0.001)$ exceeded pre-operative values (1.6-fold) and was significantly higher in comparison with LSSI-F $(p=0.001)$ and LSSI $(p=0.002)$. The NO index did not differ much from the preoperative index and did not have statistically significant differences ( $p>$ 0.05 ) from the values of the LSSI and the LSSI-F.

The effect of anxiety-depressive disorders on the level of indices of pro-inflammatory cytokine status and endothelial function in patients with combined abdominal pathology was established. The severity of anxiety and depressive disorders was clustered as closely as possible between themselves $(r=0.88, p$ $<0.001$ ) and at a moderate correlation level with ET-1 level $(r=0.35, p<0.05$ and $r=0.46, p<0.05$, respectively); anxiety disorders at the level of mean correlations were associated with IL-8 $(r=0.69, p$ $<0.01)$ and NO $(r=0.68, p<0.01)$. The severity of depressive disorders strongly correlated with the IL-6 index ( $r=0.75, p<0.001)$, moderately with TNF-a ( $r=$ $0.42, p<0.05)$. A direct relationship between the high level of anxiety-depressive disorders and the severity of the systemic inflammatory reaction in the postoperative period has been established, which confirms their role as an unfavourably predictive marker.

Several studies have demonstrated that laparoscopic surgery, including laparoscopic cholecystectomy and hysterectomy, are associated with lower levels of IL-6 and CRP compared with open procedures [11, 12]. Patients with higher levels of proinflammatory markers are more likely to have postoperative complications [13]. Along with the upregulation of proinflammatory cytokines and acutephase proteins in response to surgical stress, there is activation of the hypothalamic-pituitary-adrenal axis that leads to an elevation in counter-regulatory hormones including cortisol, growth hormone, glucagon, and catecholamines.

One of the main surgical concerns regarding the hormonal stress response is the development of insulin resistance through the combination of catecholamine release and impaired immune function [14]. Catabolic hormones and inflammatory mediators also lead to salt and water retention [15]. In response to surgical injury, mitochondria activity is suppressed with an overall reduction of ATP levels. The increased inflammatory response following surgery leads to increased production of reactive oxygen species (ROS). ROS damage lipids, proteins, and even DNA can lead to impaired vascular permeability. In combination with the release of corticotropin-releasing hormone from the hypothalamus, impaired vascular permeability can eventually result in delayed gastrointestinal function and impaired anastomoses in colorectal procedures [16].

Cell disruption from direct surgical manipulation releases a number of intracellular mediators, including potassium, prostanoids, bradykinin, nerve growth factors, cytokines, and chemokines, which can then cause peripheral sensitization of nociceptors. In addition to these proinflammatory mediators, substance $\mathrm{P}$, and calcitonin gene-related peptide also sensitize nociceptors in adjacent tissues that were not directly injured by surgical trauma. Ultimately, this leads to central sensitization through NMDA receptors in the dorsal horn of the spinal cord and can lead to the development of hyperalgesia, allodynia, and possible chronic postsurgical pain [15].

\section{CONCLUSIONS}

Thus, in the course of the comparative analysis, a general trend was established: the simultaneous surgical interventions caused intensification of proinflammatory cytokines and changes in the functional state of the endothelium. In this case, laparoscopic SSI in combination with "Fast Track Surgery" contributed to a less pronounced systemic inflammatory response of the patient's body to an operational trauma, which in turn significantly increased the effectiveness of simultaneous treatment and the quality of life of patients. The results confirm the advantages of using laparoscopic access over the traditional when performing simultaneous surgical interventions on the organs of the abdominal cavity, small pelvis and anterior abdominal wall. In all groups, a direct relationship was established between the high level of anxiety-depressive disorders and the severity of the systemic inflammatory response in the postoperative period, which confirms their role as an unfavorably predictive marker and points to the need for standardizing not only the methodology of surgical intervention, but also the tactics of preoperative management of this category of patients using psychocorrectional programs, which will increase the effectiveness of treatment and rehabilitation activities.

It has been established that in $100.0 \%$ of cases the combined abdominal pathology is comorbid with 
anxiolytic disorders and interoceptive somatogenic depression of varying severity, which indicates the need for screening in the preoperative period with the aim of identifying psychoemotional disorders. The combined use of laparoscopic simultaneous interventions and multimodal concept of "Fast Track Surgery" with simultaneous surgical interventions has undeniable advantages in the treatment of combined pathology of the abdominal cavity, small pelvis and anterior abdominal wall: minimizing the operational stress contributes less pronounced systemic inflammatory reaction of the patient's body to an operational trauma, which, in turn, significantly improves the effectiveness of simultaneous treatment and the quality of life of patients. Given the direct connection between the high level of anxietydepressive disorders and the severity of the systemic inflammatory reaction in the postoperative period, in our opinion, it is expedient to develop and implement, in the framework of the "Fast Track Surgery" concept, standardized psycho-correction programs aimed at leveling the anxiety-depressive disorders, which will allow to optimize the effectiveness of treatment and rehabilitation measures.

\section{REFERENCES}

[1] Vertkin AL, Rumyantsev MA, Skotnikov AS. Comorbidity. Clin Med 2012; 90(10): 4-11.

[2] World Report on Ageing and Health. World Health Organization. [updated 2015 Oct 30; cited 2016 Feb 10]: Available from: http://www.who.int/ageing/events/worldreport-2015-launch/en

[3] Vertkin AL, Sotnikov AS. Comorbidity. Kazan Med Zh 2014; 95(2): 292-296.

[4] Kehlet $H$. The surgical stress response: should it be prevented? Can J Surg 1991; 34(6): 565-567.
[5] Kehlet H. Fast-track surgery - an update on physiological are principles to enhance recovery. Langenbecks Arch Surg 2011; 396(5): 585-590. https://doi.org/10.1007/s00423-011-0790-y

[6] Antipin EE, Uvarov DN, Antipina NP, Nedashkovsky EV Sovershaeva SL. Early multimodal rehabilitation with abdominal hysterectomy - an impact on the postoperative period. Anesthesiol Reanimatol 2013; 6: 37-41.

[7] Antipin EE, Uvarov DN, Svirsky DA, et al. Implementation of the principles of Fast Track in cesarean section. Anesthesiol Reanimatol 2011; 3: 33-36.

[8] Krasnov VN. Ethical problems of modern psychiatry. Indep Psychiatr J 2002; 3: 12-17.

[9] Talismanov VS, Popkov SV, Zykova SS, Karmanova OG, Tsaplin GV. Study of the stereoisomeric composition of biologically active substituted 1-[(1,3-dioxolan-4-yl)methyl]$1 \mathrm{H}-1,2,4$-triazoles and 1-[(1,3-dioxolan-4-yl)methyl]-1Himidazoles by NMR spectroscopy techniques. J Pharm Sci Res 2018; 10: 2041-2044.

[10] Burkitbaev ZhK, Raisov SD, Turganbekova AA, et al. HLA Alleles in Kazakhstan and in the global genofund. Gematol Transfusiol 2015; 60(2): 52-56.

[11] Kim TK, Yoon JR. Comparison of the neuroendocrine and inflammatory responses after laparoscopic and abdominal hysterectomy. Korean J Anesthesiol 2010; 5(9): 265-269. https://doi.org/10.4097/kjae.2010.59.4.265

[12] Jakeways MS, Chadwick SJ, Carli F. A prospective comparison of laparoscopic versus open cholecystectomy. Ann R Coll Surg Engl 1993; 75: 142.

[13] Podgoreanu MV, Michelotti GA, Sato $Y$, et al. Differential cardiac gene expression during cardiopulmonary bypass: ischemia-independent upregulation of proinflammatory genes. J Thorac Cardiovasc Surg 2005; 130: 330-339. https://doi.org/10.1016/j.jtcvs.2004.11.052

[14] Carli F. Physiologic considerations of enhanced recovery after surgery (ERAS) programs: implications of the stress response. Can J Anesth Can Anesth 2015; 62: 110-119. https://doi.org/10.1007/s12630-014-0264-0

[15] Feldheiser A, Aziz O, Baldini G, et al. Enhanced recovery after surgery (ERAS) for gastrointestinal surgery. Part 2 : Consensus statement for anaesthesia practice. Acta Anaesthesiol Scand 2016; 60: 289-334. https://doi.org/10.1111/aas.12651

[16] Chowdhury $\mathrm{AH}$, Lobo DN. Fluids and gastrointestinal function. Curr Opin Clin Nutr Metab Care 2011; 14: 469-76. https://doi.org/10.1097/MCO.0b013e328348c084

\section{DOI: https://doi.org/10.6000/2292-2598.2019.07.03.10}

(C) 2019 Gumenyuk et al.; Licensee Lifescience Global.

This is an open access article licensed under the terms of the Creative Commons Attribution Non-Commercial License (http://creativecommons.org/licenses/by-nc/3.0/) which permits unrestricted, non-commercial use, distribution and reproduction in any medium, provided the work is properly cited. 